\title{
Long-term Potentiation Is Associated with New Excitatory Spine Synapses on Rat Dentate Granule Cells
}

\author{
Mari Trommald, Gunn Hulleberg, and Per Andersen ${ }^{1}$ \\ Department of Neurophysiology \\ Institute of Basic Medical Sciences \\ University of Oslo \\ 0317 0slo, Norway
}

\section{Abstract}

To investigate possible morphological correlates to long-term potentiation (LTP), three-dimensional reconstruction of serial electron micrographs was employed. LTP was induced in the perforant path/dentate granule cell synapse in two rats. The surgically isolated contralateral side served as control, along with two untreated animals. Longitudinally sectioned and transversally sectioned dendrites were sampled from the middle fifth of the molecular layer and all visibly connected spines were identified. A mixed, unbalanced, nested variance component model was used to make a valid statistical comparison between the LTP and control groups.

The spine density was higher in the experimental than in the control groups. The changes were statistically significant in both the longitudinal and transverse sample. In addition, spines with a divided stem and two heads (bifurcating spines) were seen at a higher frequency in the LTP material compared with the contralateral material. From a subset of dendrites all connected spines were reconstructed and detailed measurements of head, neck, and PSD dimensions were made. We failed to find significant differences following LTP on either of the dimensions measured. The results suggest that new spine synapses are formed following LTP, including some of the bifurcating type.

\footnotetext{
${ }^{1}$ Corresponding author.
}

\section{Introduction}

The hippocampal formation is important for spatial navigation in rodents. Surgical or excitotoxic lesions of the hippocampal formation results in reduced learning behavior in a spatial learning task like the water maze (Morris et al. 1986; Morris et al. 1990). Rodents that are dependent on good spatial navigation like long-ranging male prairie voles have larger hippocampi than closely related species with smaller territories or nonroaming female voles (Jacobs et al. 1990). Furthermore, food-storing species of birds also have a larger volume of the dorso-medial cortex, a likely avian counterpart of the hippocampus (Krebs et al. 1989). Hippocampal damage in man causes large learning and memory deficits, including those coupled to spatial behavior (Squire 1992).

In a search for basic mechanisms that might subserve the hippocampal participation in learning behavior, a process that strengthens certain synapses would be an interesting candidate, in particular if it had sufficient duration to fit the long duration of spatial learning. Long-term potentiation (LTP) is a cellular model that has several properties suitable for a role in learning behavior (Bliss and Collingridge 1993). First, LTP can be induced by repetitive activity of afferent impulses within the physiological range of hippocampal neurons. Second, the effect is very long-lasting, up to several weeks or even months in an awake, behaving animal (Bliss and Gardner-Medwin 1973; Barnes 1979). Most important, long-term potentiation allows associativity between synapses belonging to two afferent systems. Simultaneous activation of NMDA ( $N$-methyl-D-aspartate)-receptor operated synaptic channels and AMPA ( $\alpha$-aminohydroxy-isoxazole-propionate)-receptor controlled synaptic channels strengthens the latter (Wigström

LEARNING \& MEMORY 3:218-228 @ 1996 by Cold Spring Harbor Laboratory Press ISSN1072-0502/96 \$5.00

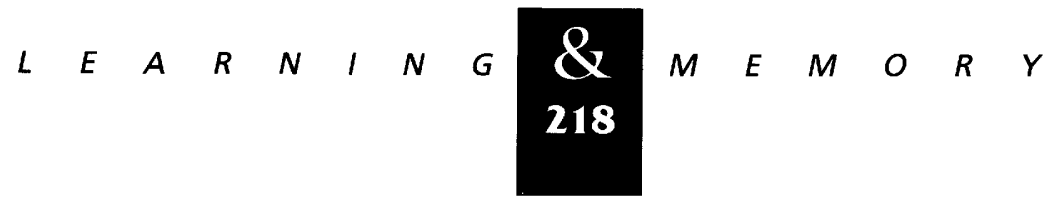


al. 1986). An essential mediator of the induction process is the postsynaptic influx of calcium ions through activated NMDA-receptor channels (Nowak et al. 1984). Because excitatory synapses on hippocampal pyramidal cells and dentate granule cells are located mainly to dendritic spines, calcium ions are likely to be concentrated in the spine heads. The observation that LTP induction requires a minimal strength of the electrical tetanic stimulation (Bliss and Gardner-Medwin 1973) gave birth to the cooperativity hypothesis, which proposes that a certain number of tetanized fibers need to be activated before the process is set in action (McNaughton et al. 1978).

Of the LTP properties, the duration is particularly challenging because the long duration suggests a structural rearrangement as a likely candidate, for example, an increased number of synapses between neurons in essential parts of the network. In fact, long-lasting LTP forms require protein synthesis (Krug et al. 1984) that may be required to create newly formed structures. In similar ways, learning behavior in invertebrates and birds has been associated with a remarkable increase in the spine coverage of various cells taking part in the learning (Bailey and Chen 1988; Rose 1991).

A substrate for long-term changes in a neuronal network may be of two types, either changes of pre-existing elements or a physical alteration of the network by addition or removal of structural elements like fibers, boutons, spines, or even dendritic branches. The first type of change would be expressed as an alteration of one or more dimensions of the structures involved, whereas the second would mean changes in connectivity seen as an up- or down-regulation of the synaptic density in parts of the network. For both types the specificity of the plastic changes is likely to be maintained if the changes are restricted to the most intensively used neuronal elements.

Previous two-dimensional electron microscopical work has reported that high-frequency stimulation of afferent pathways may result in rapid increases of the dimensions or shape of existing spines (Fifkova and Van Harreveld 1977; Fifkova and Anderson 1981; Desmond and Levy 1986; Geinisman et al. 1991, 1993). In addition, claims to synaptogenesis have appeared (Lee et al. 1980; Chang and Greenough 1984). In these two reports from CA1 an increase of shaft and sessile spine synapses was found and expressed as number of spines per unit area of two-dimensional electron micrographs without stereological correction. However, shaft synapses are considerably more abundant on interneurons than on pyramidal cells. Without information on the relative contribution of dendrites from these two cell types, the results are difficult to interpret. Furthermore, our own observations indicate that the majority of socalled sessile spines turn out to be standard spine synapses after three-dimensional reconstruction. However, Hosokawa et al. (1995) also reported increased length and changed orientation of dendritic spines in identified CA1 pyramidal cells by confocal imaging of chemically induced LTP in living slices.

In a preliminary investigation, also using three-dimensional reconstruction from serial electron micrographs (Trommald et al. 1990), we reported an increased spine density after LTP. In the present investigation, we have further analyzed the morphological changes induced in the medial perforant path synapses by LTP, using the same technique. Both the dimensions, density, and distribution of dendritic spines have been measured from three-dimensional reconstructions. We found only feeble changes of spine dimensions, but significant changes in spine density, pointing to an altered connectivity after LTP.

\section{Materials and Methods}

\section{ANIMALS}

Adult rats $(250-280 \mathrm{~g})$ were anesthetized with a mixture of urethane and chloralose $(1 \mathrm{~g}$ and $40 \mathrm{mg}$ per $\mathrm{kg}$, respectively, given intraperitoneally) and fastened in a stereotactical apparatus. Recording and stimulation electrodes were made of lacquer-insulated tungsten wire and placed to stimulate the medial perforant path and to record from the dentate molecular layer more rostrally. The coordinates for the stimulation electrode were $7.2 \mathrm{~mm}$ behind bregma and $2.8 \mathrm{~mm}$ lateral to the midline. For the recording electrodes they were $5.2 \mathrm{~mm}$ behind bregma and $4.3 \mathrm{~mm}$ lateral to the midline. The signals typical for the dentate area in response to stimulation of the medial perforant path were used to locate the recording electrode (Andersen et al. 1966). A position $50 \mu \mathrm{m}$ dorsal to the reversal point for the field excitatory postsynaptic potential (fEPSP) was used to record the synaptic activity of the medial perforant path synapses. In two animals, a parasagittal section

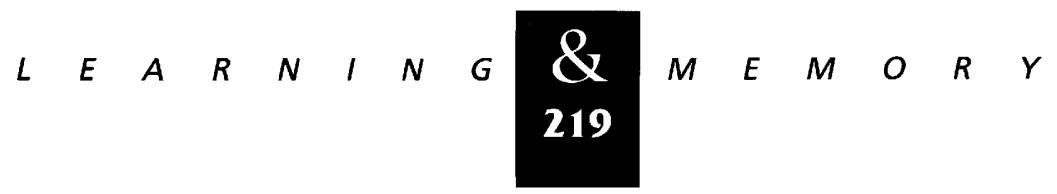


was placed close to the midline to prevent impulses from crossing over to the contralateral hippocampus. In these animals, the homotopic area of the contralateral, nonstimulated hippocampi was used for control. Another type of control was dentate tissue taken from the same region in normal rats anesthetized in the same manner, but without any stimulation.

\section{STIMULATION AND RECORDING}

LTP was induced by $100 \mathrm{~Hz}$ stimulation for 1 sec. This tetanic stimulation was repeated 10 times with intervals of $30 \mathrm{sec}$. The responses to singleshock stimulation before tetanization were used as baseline, and LTP was measured as an increased slope of the fEPSP. The degree of LTP was assessed by comparing two input/output curves, one taken before, and one taken $30 \mathrm{~min}$ after the last tetanization. To secure that the examined tissue had undergone LTP changes, blocks selected for electron microscopy were taken from the region from which LTP was recorded or its immediate neighborhood ( $<0.5 \mathrm{~mm}$ lateral or medial), well inside the strip of excited granule cells or lamella (Andersen et al. 1971). The position of the recording electrode was marked by removing the electrode, painting it gently with a methylene blue solution, and reinserting it into the same track, but to a depth $0.5 \mathrm{~mm}$ short of the original position. By this procedure, a small area of the dorsal surface of the hippocampus was colored so that the appropriate area could be removed for further processing.

\section{FIXATION AND ELECTRON MICROSCOPY}

Thirty minutes after the last tetanization had produced well-developed LTP, the animals were taken out of the frame and intracardially perfused with $200 \mathrm{ml}$ of cold $\left(4^{\circ} \mathrm{C}\right)$ mammalian Ringer's solution followed by a mixture of $2.5 \%$ glutaraldehyde and $3.0 \%$ formaldehyde in $0.1 \mathrm{~m}$ phosphate buffer $(\mathrm{pH} \mathrm{7.4)}$ at room temperature. The hippocampal formation was taken out and three $\sim 0.5 \mathrm{~mm}$ thick transverse sections were taken out, one block with the methylene blue mark, and the two immediately adjoining blocks flanking the marked area. The control tissue was processed in the same way as described.

\section{ELECTRON MICROSCOPY}

After 3-20 hr in aldehyde solution, the blocks were postfixed for $1 \mathrm{hr}$ in $1 \%$ osmium tetroxide in cacodylate buffer ( $\mathrm{pH}$ 7.6). The blocks were dehydrated and embedded in epoxy resin. Serial sections (15-55 in unbroken sequence) were made from the dorsal blade of the dentate area. The section thickness was measured by vacuum deposition of carbon on both sides of a set of sections with subsequent reembedding and electron micrographs of transverse sections of the original metacrylate section. The average thicknesses were $53 \pm 3$ nanometer (diamond knife) and $68 \pm 6$ nanometer (glass knife). Initially, a series of sections were taken at low magnification $(\times 700)$ to form a continuous strip from the hippocampal fissure through the granule cell layer. On this strip, we marked the position of the hippocampal fissure and the upper part of the granular layer and measured the thickness of the molecular layer. This thickness was also measured at a number of points in semithin sections from the same blocks counterstained by paraphenyldiamine. All further analysis was made in a region between two lines drawn parallel to the granule layer to delimit our study to perforant path synapses in the middle fifth of the molecular layer. By using tissue within a block with physiologically demonstrated LTP and from adjoining blocks not more than $0.5 \mathrm{~mm}$ away, we ascertained that the analyzed tissue had undergone LTP changes. The spread of activity from stimulation in the region of the angular bundle is considerably larger than the lateral separation of the three neighboring blocks (Lømo 1971).

Sections were made in two planes, one along the main axis of the granule cell dendrites and parallel to the perforant path fibres, and the other parallel to the granular layer. These planes of section were called longitudinal and transverse, respectively. For spine density measurements, a final magnification of 15,000 or 20,000 was used. A subset of dendrites were photographed at a final magnification of 40,000 for measurements of spine dimensions.

\section{SELECTION CRITERIA}

Longitudinal dendrites with appearance typical for dentate granule cells and with long segments $(>12 \mu \mathrm{m})$ parallel to the plane of section

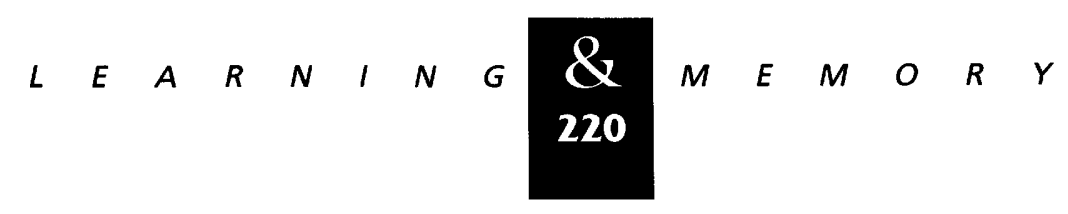




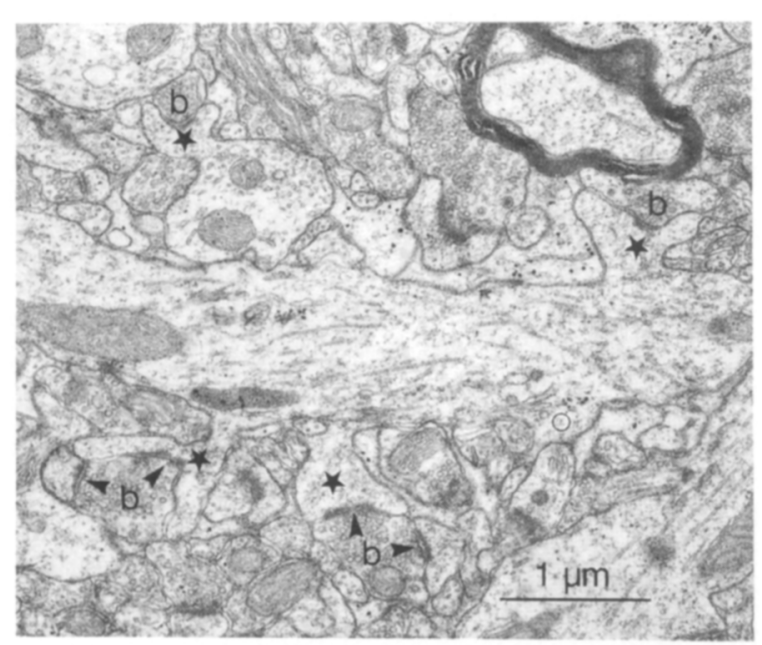

Figure 1: Electron micrograph from the middle fifth of the dentate molecular layer. Spines are indicated with stars and possible active sites by arrowheads. (O) Spine root; (b) boutons.

were selected for analysis (Fig. 1). When such a segment was found roughly in the middle of a series of sections, we photographed corresponding parts of the neighboring sections in both directions to include as much of the dendrite as possible. The criteria for including spines in this material was that the spine neck could be clearly seen emerging from the dendritic branch to the spine head (Fig. 1, star) where an asymmetric synapse was formed between a bouton (Fig. 1, b) and the spine. Dendritic protrusions that did not meet these criteria (Fig. 1, circle) were omitted from the data set. Once a dendrite with all its connected spines were marked, the spine profiles were traced with a digitizing tablet and transferred to a computer program. With the program PDIS (courtesy T.W. Blackstad, J. Bjaalie, and E. Andersen, University of Oslo, Oslo, Norway), we reconstructed the dendritic spines by superimposing neighboring tracings. The superimposition was made by eye, using typical landmarks seen in all the relevant sections, like mitochondria or myelin figures to coordinate the orientations of the sections.

The transverse diameter of the spine neck was measured at a set of positions along the neck, each either 30 or $60 \mathrm{~nm}$ apart, using a stereoscopical presentation to estimate the virtual contours. The procedure was repeated for each of a set of rotational angles. The different transverse diameters were measured and entered in a polar diagram to calculate the cross-sectional area.

\section{ANALYSIS}

The length of the dendritic segments was measured from projections of the three-dimensional reconstruction. The spine density was calculated as the number of identified spines per length of dendritic segment without compensation for shrinkage. The spine neck length, total spine length, and head diameter were calculated with an interactive program with three-axis rotation of the digitized tracings. Most spine heads had an ellipsoid shape (Trommald and Hulleberg 1996) and appropriate algorithms were used for volume estimations. This method was preferred to summation of the areas of individual sections through the head for two reasons: It includes the two sphere segments at the edge of the spine head which the disk addition method neglects, and it also avoids the latter method's interpolation problems between neighboring disks. The ellipsoid method gave $\sim 10 \%$ higher values than the disk addition method. Some spines were invaginated, and the volume of the hollow was fitted by a smaller ellipsoid and subtracted from the larger ellipsoid circumscribing the head. The PSD area was inspected by rotation and classified as flat, concave, or convex. For the concave and convex spines the shape was characterized as part of either a sphere or of a cylinder, after which the PSD area was unfolded into a globular or rectangular shape, respectively, and their area measured using appropriate equations. Finally, the depth of the curvature was measured in a plane at $90^{\circ} \mathrm{C}$ to the longest axis of the PSD envelope.

\section{STATISTICS}

Several features of the data set must be considered to select a proper statistical method. First, the data derive from a small number of animals. Second, many of the relatively small number of dendritic segments come from the same rat, requiring nesting of the spine density variable to the higher order variable (rat). However, the dendritic segments are unlikely to be samples from the same cell, given the large number of intermingled dendrites in the tissue and the usual selection of only one dendritic segment from each EM block. Third, the number of segments in the experimental and control group differ, representing an unbalanced situation. Finally, the model was mixed because there was a fixed group effect (the groups to be compared were defined beforehand)

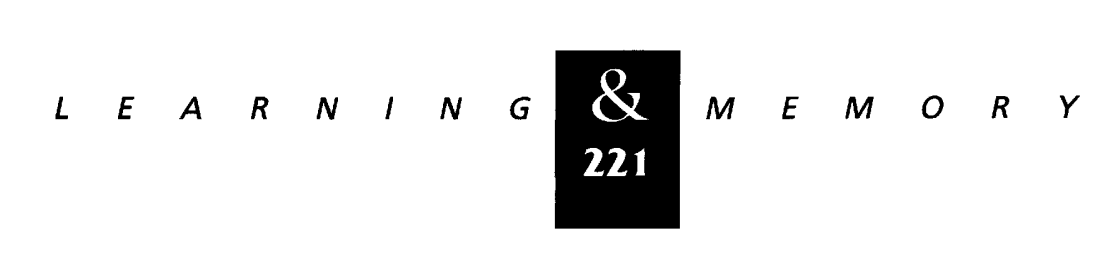


and a random rat effect. To take care of these conditions we used an unbalanced, nested, mixed variance component model. Standard analyses of variance (ANOVA) tables were replaced by estimation of parameters based on restricted maximum likelihood estimation (Searle et al. 1990). Because the data obtained from the reconstructed dendritic segments depend statistically on the rat they are derived from, the variance component model nested the variables to the higher order variable.The rats may be considered as sampled from the same distribution of animals. The basic analysis of variance equation was $\mathrm{y}_{i j k}=\mu+\tau_{i}+\beta_{(j) i}+\epsilon_{(i j) k}$, where $i=1, \ldots, a ; j=1, \ldots, b_{i}$; and $k=1, \ldots, n_{i j}$. In our case, $a=2$ (the LTP and the control tissue), $b$ gives the number of rats in the two groups and $k$ is the number of dendritic segments from a given rat, each providing one spine density measurement. The number of segments from each rat is denoted by $n_{i j}$. Therefore, $y_{i j k}$ is the $k$ th spine density (response) value for rat $j$ in group $i$; $\mu$ represents the overall fixed effect (mean of the total population of spine densities ); $\tau_{i}$ is a fixed effect depending on the treatment (LTP); $\beta_{(j) i}$ is a random rat effect, and, finally, the $\epsilon_{(i j) k}$ is a random error effect. We treated $\mathrm{b}_{(j) i}$ as independent, random variables with standard deviation $\sigma_{\beta}$ and 0 expectation. Finally, the error terms were assumed to be independent with a standard deviation of $\sigma$.

The variance of the observations may be decomposed into contributions from rats and an error term. Because the experimental and control tissue came from the same rat, the contribution to the variance from the rats could be calculated separately. The $\boldsymbol{P}$ values were calculated, assuming that the variance components were normally distributed. To test whether the LTP group had increased spine density, i.e., if $\tau_{1}>0$, we used the standard statistic obtained by dividing the estimated value with the corresponding estimated standard deviation. For spine dimension measurements, we had too few dendrites to make meaningful estimates of the rat variance. The spines were, therefore, nested under dendrites only.

\section{Results}

\section{DENDRITIC VARIABILITY}

From the serial electron micrographs a number of dendritic segments belonging to granule cells were reconstructed from the LTP and from the control material. In Figure 2A two examples from each material are shown. There was a definite variability between various segments, regarding the type of spines, their shape and length, and the density along the dendrites. In spite of the variability, we conclude that all reconstructed segments belong to the same category as judged by their appearance (light cytoplasm, regularly spaced microtubules of roughly similar orientation), and relatively even diameter. The spine density in transverse sections was strikingly higher than in longitudinal sections (Fig. 2B; Fig. 3). This indicates that the longitudinal sections are less than optimal for detecting spines. The reason for this inconsistency appeared when the spine root position was plotted on the dendritic surface of one longitudinal sectioned dendrite. The detected spines emerged from the lateral sectors and comprised $\sim 50 \%$ of the total perimeter. Hence, the actual longitudinal spine density is probably twice the estimated value. Spines emerging from the upper and lower surfaces of the dendrite were not detected. The failure was probably attributable to

A

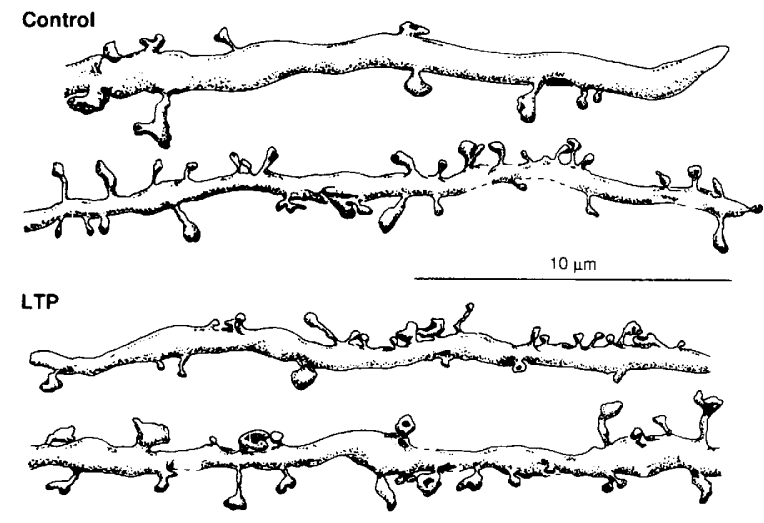

B
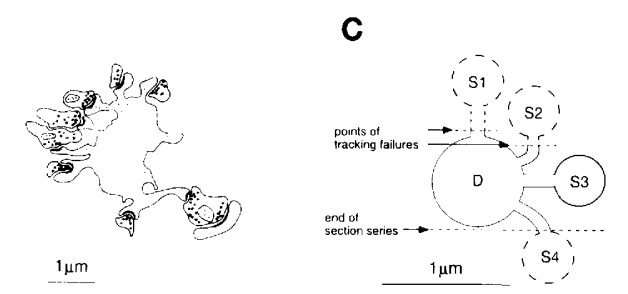

Figure 2: (A) Reconstruction of four dendritic segments, two from the control material (top) and two from the LTP material (bottom). (B) Tracing of a transversally sectioned granule cell dendrite. (C) Diagram of a transversally sectioned dendrite illustrating difficulties in tracking certain spine necks.

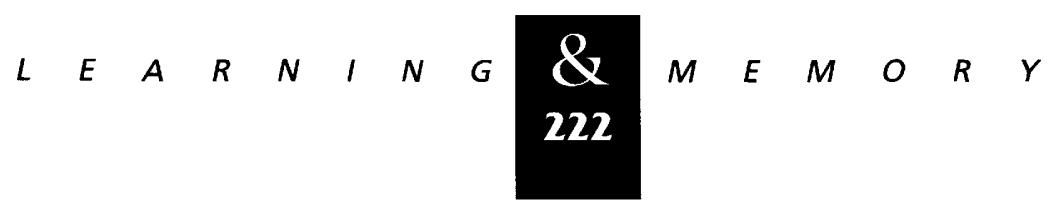




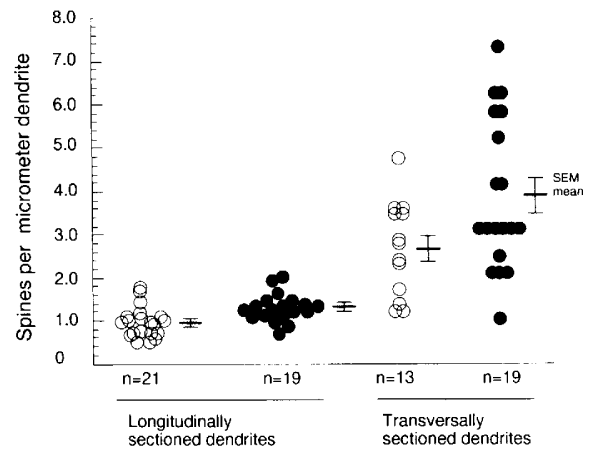

Figure 3: Graph of the spine density in spines per $\mu \mathrm{m}$ dendritic length from control $(O)$ and LTP material $(O)$. $(n=2$ rats). Data from longitudinally (left) and transversally (right) sectioned dendrites. Heavy bars give represent values; light bars, S.E.M.

the difficulty of following the thin cross-sections of spine necks through consecutive sections when cut at right angles (Fig. 2C, S1 and S2), and partly because some spines could not be traced to an active site of a presynaptic bouton, one of the identification criteria (Fig. 2C, S4). Finally, some spines escaped us because parts of the dendrite was truncated. The extremely close packing of profiles and thin spine neck diameter seen in some of the transverse sections (Fig. 2B) help to explain why it is difficult to follow these closely located structures when they are transversally sectioned. On the other hand, because the transverse sections could be followed for short dendritic lengths only, they were not ideal for spine density measurements either.

\section{SPINE DENSITY MEASUREMENTS}

The tissue expressing LTP for $30 \mathrm{~min}$ showed a significant increase in spine density, both in longitudinally and transversally sectioned dendrites. In the longitudinal sample, the spine density was calculated from 19 dendritic segments (286 spines) taken from two rats with LTP and compared with 21 dendritic segments (299 spines) taken from the nontetanized contralateral side of the same animals (Fig. 3). The average spine density value and standard deviation (S.D.) in the LTP material measured 1.28 (s.D.0.335) spines $/ \mu \mathrm{m}$ against 0.97 (S.D.0.35) in the control material. The difference was highly significant when tested by the variance component model $(P=0.004)$ (Fig. 3 ). In transverse sections, the LTP material $(n=19$ dendritic segments, 75 spines) gave a mean value of 3.87 (s.D. 1.76) against 2.66 (S.D. 1.10) spines/ $\mu \mathrm{m}$ in the control tissue ( $n=13,48$ spines). The same model was applied as in the longitudinal sample, and again, the difference was statistically significant $(P=0.02)$.

\section{SPINE DIMENSIONS}

A total of 125 spines from four dendritic segments from LTP tissue were reconstructed threedimensionally. The dimensions measured were three orthogonal head diameters, the PSD area, the area of a set of equally spaced neck cross-sections, and the neck length. These data sets were compared with 115 spines reconstructed from six control dendrites, each from a separate granule cell (two from the surgically isolated contralateral side in LTP experiments, four from naive rats). A total of 12 protrusions in the experimental and 6 protrusions in the control material were omitted from the data sample because we failed to identify a synaptic region contacting adjacent boutons. Alternatively, these structures could be spines in the making, as discussed later. The head volume, the PSD area, the minimum neck diameter, and the total spine length were compared with the control sample (Fig. 4). The plots show that all distributions, in both experimental and control material, are skewed toward larger values. Although both the mean values and the ranges were somewhat higher in the LTP material, no changes were statistically significant. For the minimal cross-sectional area the changes toward wider necks in the LTP tissue were close to significance with $P=0.052$. For the other three dimensions the $P$ values were considerably larger than 0.05 .

Previous reports have maintained that spines can be divided into classes according to their size (Peters and Kaiserman-Abramof 1970; Harris and Stevens 1989), and that such differences in shape might reflect uneven synaptic efficiency (for review, see Harris and Kater 1994). In a similar analysis of the control material we failed to detect spine classes based on distribution histograms or scatterplots (Trommald and Hulleberg 1996). After LTP induction, neither distribution plots of head volume, minimal cross-sectional area, PSD area, nor spine length revealed any multimodality in the distribution plots (data not shown). The distributions of both our normal and LTP material were, for example, well fitted by a

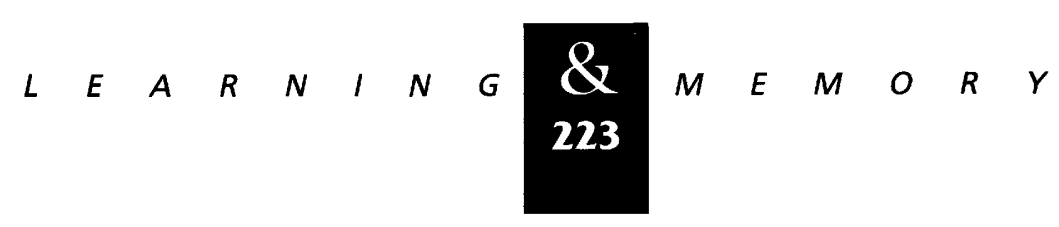


Trommald et al.

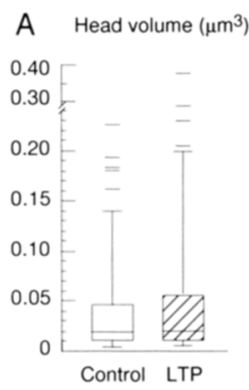

C Minimal neck cross-

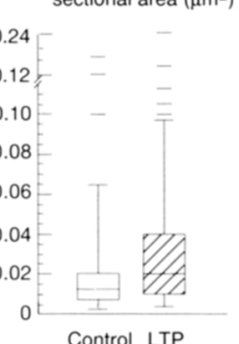

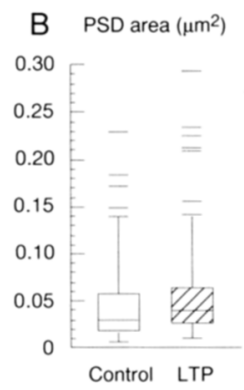

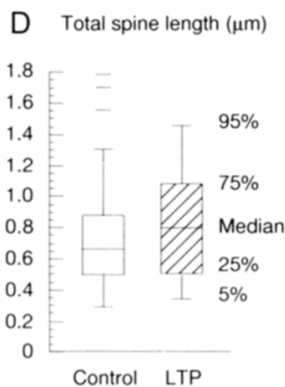

Figure 4: Graphs of spine dimensions in control and LTP material. (A) Head volume; $(B)$ area of the postsynaptic density; $(C)$ area of the smallest cross-section; $(D)$ total spine length (from the dendrite to the top of the head). Boxed area give values between $25 \%$ and $75 \%$ of the observations. Horizontal lines indicate observations outside the $95 \%$ percentile.

lognormal distribution (Kolmogorov-Smirnov statistics, $P>0.05$ ), arguing against the existence of identifiable spine classes. Similar results were found for the minimal cross-sectional area of the spine neck, the spine length, and the PSD area. In both the LTP and control group, the PSD area showed a large variability in shape from a simple disk shape to large irregular shapes with several fingerlike protrusions. Six of 115 spines in the control group, and five of the 125 in the experimental group had a complete partition of their PSD regions.

\section{BIFURCATED SPINES}

Among the spines there was a small subset of bifurcating spines that had a divided stem and two heads (Fig. 5A), each contacting a separate bouton. Each of the branches of the illustrated spines made contact with a standard perforant path bouton and showed all the normal attributes of an asymmetric excitatory spine synapse. Figure 5B shows drawings of eight different bifurcated spines arranged with the largest spines at the top. The large variability of these spines is evident. There
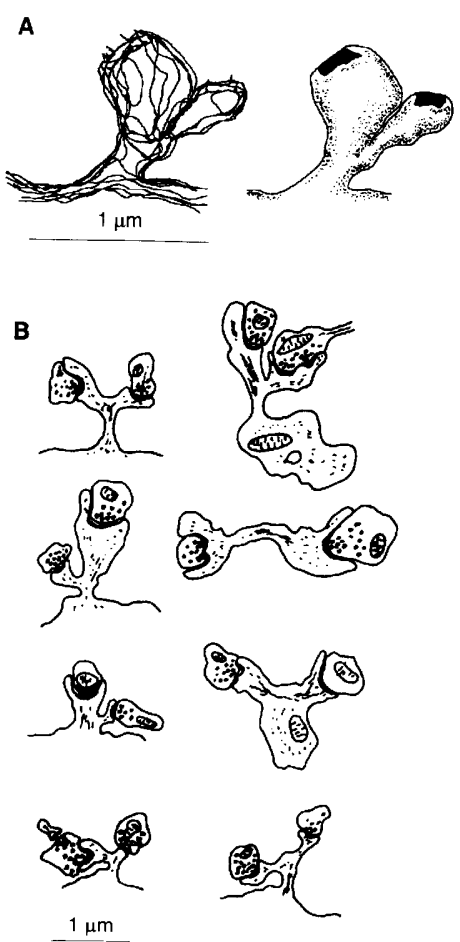

C

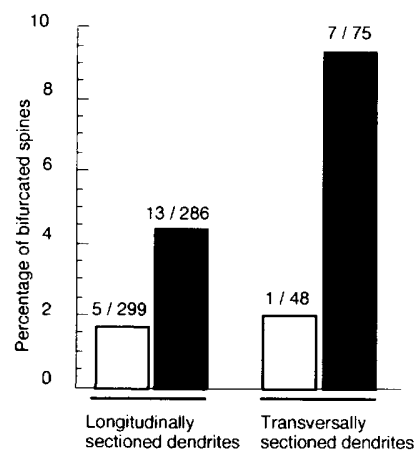

Figure 5: Bifurcated spines from the middle fifth of the dentate molecular layer. (A) Superimposed tracings from a set of sections through the spine and a spine envelope with the postsynaptic densities indicated in black. (B) Representative tracings of eight different bifurcated spines to illustrate the variability in size and form. (C) Graphs giving the number of bifurcating spines as percentage of the total number for control (open bars) and LTP material (solid bars). Data from longitudinally (left) and from transversally sectioned dendrites (right).

were six bifurcated examples among 347 spines $(1.7 \%)$ in the normal material, whereas the LTP material contained 20 spines of a total of 361 spines, or $5.5 \%$ (Fig. $5 \mathrm{C}$ ). The $\sim 3 \times$ higher bifurcated spine density in the LTP material is statistically significant with the adjusted $\chi^{2}$ test 
$(P=0.013)$. In transversally sectioned dendrites the same tendency was found with a $4.5 \times$ increase, although the difference was not significant, possibly attributable to a smaller sample.

The increased number of bifurcated spines must have appeared within a period of about 40 min after the LTP induction ( 5 min for induction, $30 \mathrm{~min}$ control period, and 5-10 $\mathrm{min}$ for the perfusion procedure). Because of the short time, we wanted to investigate whether a simple division of the pre-existing bouton and the connected spine into two parts had taken place. However, after reconstruction of 27 bifurcating spines no case was found in which the two spine heads were served by the same axon. In one case, the axon, after contacting one of the two spine heads (Fig. 6, b3), proceeded to make contact with another spine from the same dendrite (Fig. 6, b4). Finally, when reconstructing the presynaptic boutons attached to the bifurcating spines, all boutons were contacting at least one other spine in addition to the bifurcating one.

\section{Discussion}

The main result of the present investigation was the discovery of increased dendritic spine density in an area with physiologically established LTP. This increased dendritic spine density was

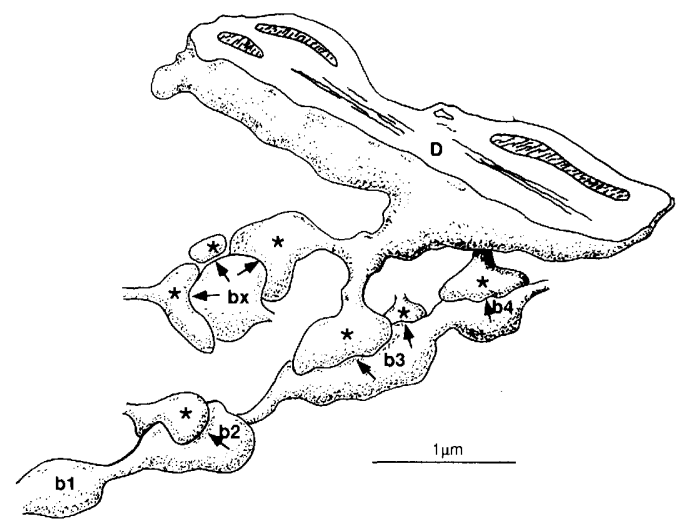

Figure 6: Reconstructed segment of a dentate granule cell dendrite with a bifurcating spine and contacting axons. The drawing is based on the basis on superimposed tracings of the relevant serial sections with removal of the contour lines to emphasize the three-dimensional relations. Spine heads are marked with stars, boutons with the letter $b$, and likely active sites with arrows. Boutons b3 and b4 from the same axon make contact with two spines from the same dendritic segment. present in both the transverse and longitudinal sample. In addition, we found an increased number of bifurcating spines in the experimental sample. The results were highly significant. The employed method for component variance analysis compensates for the uneven distribution of dendritic segments in the various groups and the nested nature of the segment data, many coming from the same rat. Because of the nature of the data sample, this statistical method is preferable to simple, uncompensated variance analysis methods because it avoids the simplifying assumptions of the latter which may give erroneous results.

There was also a tendency toward enlarged postsynaptic density area, increased minimal crossection, and lengthening of the spine neck in the LTP material. However, none of these changes reached statistical significance, although the minimal crossection data came close in having $P=0.52$ (Fig. 4). Our failure to find any statistical difference between the groups on these parameters therefore could be attributable to the relatively small number of spines.

The tissue under study was physiologically controlled and showed robust LTP. Because there was no obvious difference between the thickness of the molecular layer in the LTP and the control material, we have no reason to believe that there was a gross change of the dendritic tree as such, either by a change in the glia/neuronal volume ratio or by contraction or expansion of parts of the dendritic tree. Consequently, we conclude that the increased spine density in the dendritic segments in LTP tissue is a result of an increased number of spine synapses. New synapses are likely to have been inserted in order to explain the increased spine density.

\section{SPINE DENSITY AND TYPES}

Other investigators using EM techniques have not observed a general increased spine density in the medial perforant path zone after LTP, but either an unchanged number (Desmond and Levy 1983; Schuster et al. 1990), or even a decrease of $\sim 11 \%$ (Geinisman et al. 1991). We have no simple explanation for this discrepancy other than the unfortunate high variability in spine density between different neurons and in various tissue samples. In addition, the measurements made by the various research groups are made in clearly different ways. Both the Desmond and Levy (1983) and

$$
\begin{array}{lllllllllllllll}
L & E & A & R & N & I & N & G & \mathbf{Z}_{2} & M & E & M & O & R & Y
\end{array}
$$


Trommald et al.

the Schuster et al. (1990) studies relied upon twodimensional EM and measured spine density per volume neuropil, the former with stereological correction. Geinisman et al. (1991) used the disector technique and calculated the number of synapses per neuron. However, this group also found $\sim 11 \%$ decrease in the overall spine density in the middle third of the molecular layer, and $>30 \%$ reduction in the overall spine number in the inner third of the molecular layer where no changes were to be expected. There was also a considerable variation in the spine number between the two types of control tissue. Our own study relied upon direct measurement on individual dendritic segments, but suffers from a relatively small number of spine synapses. Hopefully, a future comparison of the two- and three-dimensional methods on the same material can solve this riddle.

Several groups have reported a change of spine configuration within the population. Thus, although Desmond and Levy (1983) reported that the number of calyciform spines increased, and Schuster et al. (1990) found the axospinous synapses with spinules to increase, both groups reported a relative reduction of simpler types. Further, Geinisman et al. $(1991,1993)$ reported an enhanced fraction of spines with segmented postsynaptic densities (PSD). Although these observations report different features, they may tie together, however, because a detailed analysis of dentate spine forms revealed a high correlation between the spine length and head size on one hand and the size and irregularity of the PSD on the other (Trommald and Hulleberg 1996). With this interpretation, the Desmond and Levy (1983), Schuster et al. (1990), and Geinisman et al. (1991) studies may all be explained if there is a change from small, simple type toward larger, more complicated spine types after LTP. A similar conclusion was drawn by Hosokawa et al. (1995) on the basis of confocal images before and after LTP induced by exposure to high $\mathrm{Ca}^{2+}$, low $\mathrm{Mg}^{2+}$ and tetraethylammonium for $10 \mathrm{~min}$. In the present report we could not find evidence for specific spine classes with regard to any of four spine dimensions, but rather a continuum of spines from simple and small to large and complex. Any change in the spine form, as suggested by Desmond and Levy (1983), Schuster et al. (1990), Geinisman et al. (1991), and Hosokawa et al. (1995), however, should have expressed itself in a changed distribution function. The remarkable speed with which the reported reorganization takes place is surprising. At most, $40 \mathrm{~min}$ lasted between the induction of the LTP and tissue fixation. However, remarkably fast growth processes has been seen in culture conditions where dendritic structures were observed to proceed toward a glutamate gradient with a speed of up to $20 \mu \mathrm{m}$ per hr (Smith et al. 1990 ). In the present case, we are talking about spine lengths of about $0.8 \mu \mathrm{m}$ within $30 \mathrm{~min}$, or $1.6 \mu \mathrm{m}$ per $\mathrm{hr}$, a tenth of the growth rate seen in culture condition. A considerably lower spine growth rate was reported by Hosokawa et al. (1995), who made confocal images of living CA1 cells during chemically induced LTP. They interpreted their distribution plots of spine lengths to mean that a fraction of spines of 1.0-1.4 $\mu \mathrm{m}$ length increased at the expense of those measuring 0.6$0.8 \mu \mathrm{m}$. This would amount to an average spine elongation of about $0.5 \mu \mathrm{m}$ within the observation time of $2.5 \mathrm{hr}$, or about $0.2 \mu \mathrm{m}$ per hr. Admittedly, the examined spines were within $75 \mu \mathrm{m}$ from the cut surface with most of the observations made only $25 \mu \mathrm{m}$ from the surface, where some structural damage often are observed. Furthermore, the spine density was as low as $0.86 \pm 0.07 \mathrm{spines} / \mu \mathrm{m}$ dendritic length as compared with values around 2.0 spines $/ \mu \mathrm{m}$ dendritic length for well stained CA1 pyramidal cells (Amaral 1990; Harris and Stevens 1989; Harris et al. 1992; Trommald et al. 1995). Thus, the observed spine dimension changes may be a response to the special experimental situation and not necessarily directly related to the induced LTP.

The fraction of identified spines in the longitudinal sample, and hence, the spine density are both lower than that shown by other techniques. We here report a detected fraction of only $50 \%$, whereas with confocal technique $73 \%$ were detected in the CA1 region (Trommald et al. 1995). Using light microscopy of Golgi-impregnated dentate granule cells $68 \%$ were detected (Desmond and Levy 1985). An important explanation is that the strict selection procedure used in the present investigation reduces the number of accepted spines. In Figure 2C, we show the main reason for failing to follow spines in the tracking procedure. The $\sim 2.5 \times$ higher spine density seen in transverse sections (Fig. 3) illustrates the degree of this loss. Reconstructions on the basis of transverse sections would, however, require much larger series of electron micrographs to get a statistically reliable number of spines. We have accepted a compromise and used both categories, assuming that in 
the longitudinal sections the detected spine fraction is the same in the control and experimental samples. Because the two samples gave the same results, we have confidence in the results even though the data set is relatively small due to the time-consuming method used.

The finding of an increased incidence of bifurcating spines and an increased spine density supports the idea that LTP may be associated with the formation of new synapses, similar to that occurring during learning in rat CA1 (Moser et al. 1994), in chick (Rose 1991), and in Aplysia (Bailey and Chen 1988). Because the twin spine heads never shared the same presynaptic element, neck splitting is probably not the mechanism for this spine formation. The same conclusion was reached by Geinisman et al. ( 1989), who observed an increased percentage of bifurcating spines in the dentate area after kindling. All bifurcating spine branches connected to boutons which already served another spine, suggesting that the bifurcating spine are produced by a growth process between two pre-existing elements, a spine and a neighboring bouton. If this is correct, we would expect to see some branchlets or spine protrusions or processes growing in nascendi, so to speak. In support of this view, both the control and the experimental samples contained several protrusions which were rejected from the spine material because they did not make contact with a bouton. Such processes are candidates for the postulated growing spine branchlets.

\section{Acknowledgments}

We thank Jorunn Line Vaaland for her expert electron microscopical processing and assistance with the analysis, Theodor Blackstad for valuable advice and discussion and use of computer programs, Jan Bjaalie and Even Andersen for use of programs and computer facilities, and Thore Egeland for statistical advice. This research was supported by grant 103582/310 from the Norwegian Research Council.

The publication costs of this article were defrayed in part by payment of page charges. This article must therefore be hereby marked "advertisement" in accordance with 18 USC section 1734 solely to indicate this fact.

\section{References}

Amaral, D.G., N. Ishizuka, and B. Claiborne. 1990. Neurons, numbers and the hippocampal network. Prog. Brain Res. 83: 1-11.

Andersen, P., B. Holmqvist, and P.E. Voorhoeve. 1966. Entorhinal activation of dentate granule cells. Acta Physiol. Scand. 66: 448-460.
Andersen, P., T.V.P. Bliss, and K.K. Skrede. 1971. Lamellar organization of hippocampal excitatory pathways. Exp. Brain Res. 13: 222-238.

Bailey, C.H. and M. Chen. 1988. Long-term memory in Aplysia modulates the total number of varicosities of single identified sensory neurons. Proc. Natl. Acad. Sci. 85: 2373-2377.

Barnes, C.A. 1979. Memory deficits associated with senescence: A neurophysiological and behavioral study in the rat. J. Comp. Physiol. Psychol. 93: 74-104.

Bliss, T.V.P. and G.L. Collingridge. 1993. A synaptic model of memory: Long-term potentiation in the hippocampus. Nature 361: 31-39.

Bliss, T.V.P. and A.R. Gardner-Medwin. 1973. Long-lasting potentiation of synaptic transmission in the dentate area of the unanaesthetized rabbit following stimulation of the perforant path. J. Physiol. (Lond.) 232: 357-374.

Chang, F.L. and W.T. Greenough. 1984. Transient and enduring morphological correlates of synaptic activity and efficacy change in the rat hippocampal slice. Brain Res. 309: $35-46$.

Desmond, N.L. and W.B. Levy. 1983. Synaptic correlates of associative potentiation/depression: An ultrastructural study in the hippocampus. Brain Res. 265: 21-30.

1985. Granule cell dendritic spine density in the rat hippocampus varies with spine shape and location. Neurosci. Lett. 54: 219-224.

1986. Changes in the postsynaptic density with long-term potentiation in the dentate gyrus. I. Comp. Neurol. 253: $476-482$.

Fifkova, E. and C.L. Anderson. 1981. Stimulation-induced changes in dimensions of stalks of dendritic spines in the dentate molecular layer. Exp. Neurol. 74: 621-627.

Fifkova, E. and A. Van Harreveld. 1977. Long-lasting morphological changes in dendritic spines of dentate granular cells following stimulation of the entorhinal area. $).$ Neurocytol. 6: 211-230.

Geinisman, Y., F. Morrell, and L. deToledo-Morrell. 1989. Perforated synapses on double-headed dendritic spines: A possible structural substrate of synaptic plasticity. Brain Res. 480: 326-329.

Geinisman, Y., L. deToledo-Morrell, and F. Morrell. 1991. Induction of long-term potentiation is associated with an increase in the number of axospinous synapses with segmented postsynaptic densities. Brain Res. 566: 77-88.

Geinisman, Y., L. deToledo-Morrell, F. Morrell, R.E. Heller, M. Rossi, and R.F. Parshall. 1993. Structural synaptic correlate of long-term potentiation: Formation of axospinous synapses with multiple, completely partitioned transmission zones. Hippocampus 3: 435-445. 


\section{Trommald et al.}

Harris, K.M. and S.B. Kater. 1994. Dendritic spines: Cellular specializations imparting both stability and flexibility to synaptic function. Annu. Rev. Neurosci. 17: 341-371.

Harris, K.M. and J.K. Stevens. 1989. Dendritic spines of CA1 pyramidal cells in the rat hippocampus: Serial electron microscopy with reference to their biophysical characteristics. J. Neurosci. 9: 2982-2997.

Harris, K.M., F.E. Jensen, and B. Tsao. 1992.

Three-dimensional structure of dendritic spines and synapses in rat hippocampus (CA1) at postnatal day 15 and adult ages: Implications for the maturation of synaptic physiology and long-term potentiation. J. Neurosci. 12: 2685-2705.

Hosokawa, T., D.A. Rusakov, T.V.P. Bliss, and A. Fine. 1995. Repeated confocal imaging of individual dendritic spines in the living hippocampal slice: Evidence for changes in length and orientation associated with chemically induced LTP. I. Neurosci. 15: 5560-5573.

Jacobs, L.F., S.J.C. Gaulin, D.F. Sherry, and G.E. Hoffman. 1990. Evolution of spatial cognition: Sex-specific patterns of spatial behavior predict hippocampal size. Proc. Natl. Acad. Sci. 87: 6349-6352.

Krebs, J.R., D.F. Sherry, S.D. Healy, V.H. Perry, and A.L. Vaccarino. 1989. Hippocampal specialization of food-storing birds. Proc. Natl. Acad. Sci. 86: 1388-1392.

Krug, M., B. Lossner, and T. Ott. 1984. Anisomycin blocks the late phase of long-term potentiation in the dentate gyrus of freely moving rats. Brain Res. Bull. 13: $39-42$.

Lee, K.S., F. Schottler, M. Oliver, and G. Lynch. 1980. Brief bursts of high-frequency stimulation produce two types of structural change in rat hippocampus. I. Neurophysiol. 44: $247-258$

Lømo, T. 1971. Potentiation of monosynaptic EPSPs in the perforant path-dentate granule cell synapse. Exp. Brain Res. 12: 46-63.

McNaughton, B.L., R.M. Douglas, and G.V. Goddard. 1978 Synaptic enhancement in fascia dentata: Cooperativity among coactive afferents. Brain Res. 157: 277-293.

Morris, R.G.M., P. Garrud, J.N.P. Rawlins, and J. O'Keefe. 1986. Place navigation impaired in rats with hippocampal lesions. Nature 297: 681-683.

Morris, R.G.M., F. Schenk, F. Tweedie, and L.E. Jarrard. 1990. Ibotenate lesion of hippocampus and/or subiculum: Dissociating components of allocentric spatial learning. Eur. J. Neurosci. 2: 1016-1028.

Moser, M.-B., M. Trommald, and P. Andersen. 1994. An increase in dendritic spine density on hippocampal CA1 pyramidal cells following spatial learning in adult rats suggests the formation of new synapses. Proc. Natl. Acad. Sci. 91: 12673-12675.

Nowak, L., P. Bregestovski, P. Ascher, A. Herbet, and A.
Prochiantz. 1984. Magnesium gates glutamate-activated channels in mouse central neurones. Nature 307: 462-465.

Peters, A. and I.R. Kaiserman-Abramof. 1970. The small pyramidal neuron of the rat cerebral cortex. The perikaryon, dendrites and spines. Amer. J. Anat. 127: 321-355.

Rose, S.P.R. 1991. How chicks make memories: The cellular cascade from c-fos to dendritic remodelling. Trends Neurosci. 14: 390-397.

Schuster, T., M. Krug, and J. Wenzel. 1990. Spinules in axospinous synapses of the rat dentate gyrus: Changes in density following long-term potentiation. Brain Res. 523: 171-174.

Searle, S.R., G. Casella, and C.E. McCulloch. 1990. Variance components. Wiley, New York, NY.

Smith, S.J., M. Cooper, and A. Waxman. 1990. Laser microscopy of subcellular structure in living neocortex: Can one see dendritic spines twitch? In The biology of memory (eds. L. Squire and E. Lindenlaub), pp. 49-71. Schattauer Verlag, Stuttgart, Germany.

Squire, L.R. 1992. Memory and the hippocampus: A synthesis of findings from rats, monkeys and humans. Psychol. Rev. 99: 195-231.

Trommald, M. and G. Hulleberg. 1996. Dimensions and density of dendritic spines from rat dentate granule cells based upon reconstructions from serial electron micrographs. J. Comp. Neurol. (in press).

Trommald, M., J.L. Vaaland, T.W. Blackstad, and P. Andersen. 1990. Dendritic spine changes in rat dentate granule cells associated with long-term potentiation. In Neurotoxicity of excitatory amino acids (ed. A. Guidotti), pp. 163-174. Raven Press, New York, NY.

Trommald, M., V. Jensen, and P. Andersen. 1995. Analysis of dendritic spines in rat CA 1 pyramidal cells intracellularly filled with a fluorescent dye. I. Comp. Neurol. 353: $260-274$.

Wigström, H., B. Gustafsson, Y.Y. Huang, and W.C. Abraham. 1986. Hippocampal long-term potentiation is induced by pairing single afferent volleys with intracellularly injected depolarizing current pulses. Acta Physiol. Scand. 126: 317-319.

Received June 24, 1996; accepted in revised form August 29 1996.

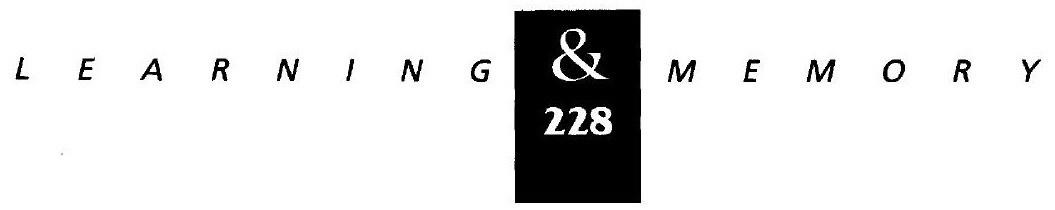




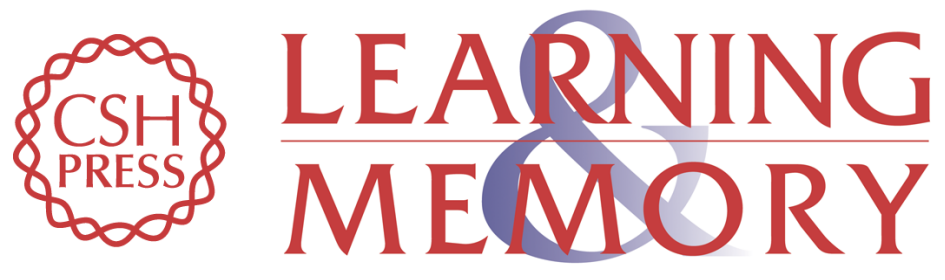

\section{Long-term potentiation is associated with new excitatory spine synapses on rat dentate granule cells.}

M Trommald, G Hulleberg and P Andersen

Learn. Mem. 1996, 3:

References This article cites 36 articles, 7 of which can be accessed free at: http://learnmem.cshlp.org/content/3/2-3/218.full.html\#ref-list-1

License

Email Alerting

Receive free email alerts when new articles cite this article - sign up in the box at the Service top right corner of the article or click here. 